\title{
Comparison of Nurses' and Families' Perception of Family Needs in Critical Care Unit at Referral Hospitals in Malawi
}

\author{
Rodwell Gundo', Feggie Bodole², Edoly Lengu' ${ }^{1}$, Alfred Maluwa ${ }^{3}$ \\ ${ }^{1}$ Department of Medical-Surgical Nursing, Kamuzu College of Nursing, Lilongwe, Malawi \\ ${ }^{2}$ Queen Elizabeth Central Hospital, Blantyre, Malawi \\ ${ }^{3}$ Research Directorate, Kamuzu College of Nursing, Lilongwe, Malawi \\ Email: aomaluwa@kcn.unima.mw
}

Received 16 February 2014; revised 18 March 2014; accepted 16 April 2014

Copyright (C) 2014 by authors and Scientific Research Publishing Inc.

This work is licensed under the Creative Commons Attribution International License (CC BY). http://creativecommons.org/licenses/by/4.0/

(c) (i) Open Access

\section{Abstract}

This study compared needs of family members as perceived by nurses and the family members themselves. The study design was descriptive and utilized quantitative data collection and analysis method. Nurses $(n=62)$ working in the Intensive Care Units (ICU) and High Dependency Units (HDU) of three tertiary health facilities in Malawi at the time of the study consented to participate in the study. In addition, family members $(n=62)$ who were looking after a critically sick relative in the ICU and HDU in the same tertiary facilities consented and participated in the study. Data were collected using a questionnaire developed from the Critical Care Family Needs Inventory for a period of 7 days. STATA version 10 was used to analyze data. The rank correlation between the mean scores of perceived needs across major need categories of support, comfort, information, proximity and assurance between the nurses and family members was significantly different from zero $(r=0.97, p=0.005)$. Nurses and family members, respectively ranked assurance $(90 \%$ and $92 \%)$ as the highest priority need, followed by information $(78 \%$ and $85 \%)$ and comfort $(78 \%$ and $84 \%)$ and then support (70\% and $73 \%)$ and proximity (66\% and $69 \%)$. The ranking however between the 2 groups on 16 out of 45 individual needs were significantly different $(p<0.05)$. Among the nurses, the rankings by registered nurses were significantly higher $(p<0.05)$ from those of nurse midwife technicians. There were also significant differences $(p<0.05)$ in the mean scores between the gender of family members with men demanding more "comfort" than females. Results show a need for facility authorities to formulate ICU policies and strategies that ensure provision of friendly services to family members of critically ill patients.

\section{Keywords}

Critical Illness, Family Needs, Nurses Perceptions, Intensive Care Unit, High 


\section{Dependency Unit}

\section{Introduction}

Families go through traumatic experiences when a relative is admitted to an Intensive Care Unit (ICU). In the majority of cases, the family members are not psychologically prepared for their relative's critical illness because most admissions occur as emergencies. Family members are caught off guard when their relatives become critically ill as a result their life becomes disorganized and disrupted [1]. The unfamiliar environment in the critical care unit, with the patient tethered to equipment, also adds to the stress of family members. The family members are at great risk for failure to cope during critical illness of their relatives.

Nurses' caring behaviour using a blend of skills, knowledge and caring attitudes helps to reduce the stress experienced by these family members [1]. Family-centred care is a notion which acknowledges that patients are part of a larger "whole”. This belief requires critical care nurses to recognize the importance of including patients' families in the circle of care [2]. Nurses also regard families as productive in the ICU. In a study by William [3] to identify the unique contribution that family members make towards patient care and recovery, nurses noted that it was challenging for them to know their patient better because they were either intubated or sedated. Contact with families helped them to know the person under their care. Apart from providing information about the patient, family members also help to provide emotional support to the patient. To maximise the family members' contribution to critical care they need support from the nursing staff. Using the Critical Care Family Needs Inventory (CCFNI), developed by Molter [4] and revised by Leske [5], studies have confirmed the following need categories: information, assurance, support, closeness or proximity and comfort [6] [7].

There are four general ICUs in Malawi which are located in the country’s public central hospitals. The country has a three-tier health system comprising the primary (health centres), secondary (district hospitals) and tertiary (central hospitals) health care levels. The central hospitals were set up to provide referral services to the secondary level care in their respective regions, hence have specialist doctors such as surgeons, oncologists, gynecologists, pediatricians, anesthetists, radiologists who are not available at the secondary level. Critically ill patients are referred from district hospitals to central hospitals for specialist care. Relatives of admitted patients stay at the hospital's guardian shelter where they are accommodated and prepare their meals. The central hospitals are also teaching facilities for various cadres of health workers such as medical doctors, nurses, clinical officers, anaesthetic technicians, pharmacy technicians and dental technicians among others.

The ICUs on average have a capacity of 5 beds. In a month about 30 patients comprising both adults and children requiring mechanical ventilation are admitted in each ICU. Surgical cases account for the majority of ICU admissions in Malawi [8]. There are also less than ten High Dependency Units (HDU) which are step-down units admitting patients successfully resuscitated in ICU or those whose illness or injury is not severe to warrant ICU admission. Nonetheless, many critically ill patients who would benefit from intensive care are either admitted to HDUs or general wards due to limited bed space in ICUs. All the ICUs and HDUs in public health facilities follow a standardised visiting policy which allows family members to visit their patients three times a day. In the morning the visiting hours are from 07:00 to 07:30. At midday the visiting hours start from noon to 13:00 hours and in the evening from 16:00 to 17:00 hours. In addition to the four ICUs in public central hospitals there are two other ICUs in private hospitals which charge user fees.

Compared to developed countries where intensive care practice is advanced, developing countries are constrained to render optimum critical care service due to limited resources. In many developing countries, ICUs are usually ad hoc areas within the hospital [9]. Most ICUs in sub-Saharan African countries are manned by nurses and medical assistants that have undergone some specialty training in anaesthesiology at certificate and diploma levels as opposed to anesthesiologists who are physician graduates [10] [11].

Malawi has less than five critical care nurse specialists and there is no institution that trains nurses in critical care. Consequently, State Registered Nurse Midwives (with diploma and degree) and Nurse Midwife Technicians (with certificates) provide critical care nursing in ICUs and HDUs based on their pre-service training knowledge. The lack of specialty training may compromise provision of comprehensive care to critically ill patients and their family members. Literature on the priority needs of family members of the critically ill patients is scanty in Malawi. This study was therefore conducted to find out from the family members their priority 
needs compared to the perception of nurses on the same needs.

\section{Methods}

\subsection{Design and Setting}

The study design was descriptive and utilized quantitative data collection and analysis method. Descriptive research involved observing, describing and documenting aspects of family needs [12]. This design was considered appropriate for this study because it aimed at describing the perceptions of nurses and family members themselves regarding the priority needs of the family members during the hospitalization and critical care of their sick relatives. Specifically the study objectives were to elicit nurses' perception of family needs in a critical care unit; elicit families' perception of their needs in a critical care unit; and compare nurses' and families' perception of family needs in the critical care unit.

The study was conducted in three ICUs and three HDUs at three public tertiary hospitals in Malawi. The three intensive care units were mixed units which admitted both children and adults with medical, trauma, surgical and obstetric emergencies. One high dependency unit admitted obstetric emergencies only; the other one was for surgical emergencies only and the last one was for medical emergencies.

\subsection{Data Collection}

The study participants were all nurses and all family members of patients in ICU and HDU. Data collectors were recruited to assist the participants especially the family members due to the high adult illiteracy in Malawi [13]. The data collectors were trained for 3 days prior to actual data collection on how to conduct in depth face to face interview with participants. The principal investigator and the co-investigator facilitated the training and subsequently supervised the data collection process.

The study targeted all nurses and all family members that were available during the time of the study. A total of 124 (62 nurses and 62 family members) were recruited for the study. Family members were interviewed using an in depth face to face interview guide during hospital visiting time. The members had the opportunity to choose either the English or vernacular language as a medium of communication during the interview. An appropriate version of the questionnaire was administered to each participant based on the choice of language. For the nurses, the English version of the same questionnaire was given to them for self administration. The nurses were approached and given the questionnaires to fill on their own during handover, tea or lunch break. The research team collected the filled questionnaire from the nurses the next day and data collection stopped when all consenting family members were interviewed and at least $90 \%$ of the nurses had returned the filled questionnaires. Data were collected over a period of about 7 days at each facility.

The questionnaire that was used for data collection in this study was the Critical Care Family Needs Inventory (CCFNI). The CCFNI is a validated instrument and has been used extensively to assess perceived needs of family members during critical illness of a relative. With permission from the author, Jane S. Leske, the questionnaire was translated to the vernacular language by a language teacher who is fluent in both English and vernacular languages. The primary author and another nurse specialist in intensive care, who are also fluent in both languages, validated the content of the translated version.

The questionnaire comprised two parts. The first part had items that elicited participant's demographic data. The second part comprised forty-five (45) items derived from the CCFNI. The 45 items formed five (5) major family need categories of: support (items 1 to 14), information (items 15 to 23), proximity or closeness (items 24 to 32), assurance (items 33 to 39) and comfort (items 40 to 45). Participants were asked to indicate the level of importance of each item measured on a 4-point Likert scale as follows; 1) Not important; 2) Slightly important; 3) Important; 4) Very important.

\subsection{Ethical Consideration}

The study was approved by the National Ethical Review Board in Malawi, i.e., the National Health Sciences Research Committee. Permission to collect data from the tertiary facilities was obtained from their respective Hospital Directors. Participants were verbally informed about the study and their written consent was obtained before they participated in the study. Confidentiality was maintained by using numbers to identify participants instead of their real names. 


\subsection{Inclusion and Exclusion Criteria}

To participate in the study, the nurses had to be working in the critical care units, i.e., the ICU or HDU of a tertiary facility in Malawi. All other cadre of health workers in the ICU or HDU or nurses that were not working in the critical care units were excluded from the study. Family members that had a critically ill relative in the ICU or HDU were invited to participate in the study. Family members of other patients other than those in the ICU or HDU were excluded from the study.

\subsection{Data Analysis}

Data were analyzed using STATA version 10.0 statistical software. Frequency counts, percentages, means, standard errors and range were computed for the dataset. Importance of respective family needs was measured by mean scores for each of the 45 needs in the CCFNI. A family need with the highest mean score represented the most important within the group of study participants (nurses or family members). Comparisons of means between the nurses and family members was done using the student's " $t$ " test at the $5 \%$ level of significance.

\section{Results}

\subsection{Study Participants}

A total of 62 out of 65 nurses (95\%) and 62 out of 63 family members (98\%) consented and participated in the study. Three nurses (5\%) who had earlier consented to participate by self administration of the questionnaire did not return the completed questionnaires while one family member did not consent to participate in the study for no specific reasons.

\subsection{Demographic Characteristics}

In the first group of participants, i.e., the nurses, $88.7 \%(n=55)$ were females and $11.3 \%(n=7)$ were males. Their ages ranged from 21 to 60 years with Mean $\pm 1 \mathrm{SE}$ of $31.97 \pm 1.21$. Among the nurses, the nurse midwife technicians accounted for $74.2 \%(n=46)$ while $25.8 \%(n=16)$ were registered nurses/midwives. None of the nurses, underwent any formal training in critical care nursing.

The majority of the nurses, $88.7 \%(n=55)$ had less than five years experience in critical care, $9.7 \%(n=6)$ had 6 to 10 years of experience and the remaining $1.6 \%(n=1)$ had more than 10 years of experience. There was a significant negative correlation $(r=-0.91, p=0.028)$ between the number of nurses and their years of experience, which indicates problems in retaining experienced nurses in the ICUs and HDUs of the tertiary instituions under study.

In the second group, i.e., the family members, $67.7 \%(n=42)$ were female while $32.3 \%(n=20)$ were males. Their ages ranged from 18 to 73 years with mean \pm 1 SE of $36.34 \pm 1.56$ years. The majority $(48.4 \%, n=30)$ attended primary education, followed by $40.3 \%(n=25)$ that had secondary education qualification and $11.3 \%$ $(n=7)$ had tertiary education qualification. Parents (mother or father) accounted for $45.2 \%(n=28)$ of the family members, followed by sister or brother $(21 \%, n=13)$, spouse $(19.4 \%, n=12)$, son or daughter $(4.8 \%, n$ $=3$ ) and other relatives $(9.7 \%, \mathrm{n}=6)$.

\subsection{Nurses' Perception versus Actual Needs of Family Members}

The nurses' and families' mean percentages scores on major need categories of support, comfort, information, proximity and assurance are shown in Table 1. Sperman's rank correlation was significantly different from zero $(r=0.97, p<0.005)$ becase the ranking of the participants' needs in these categories was similar as both groups ranked assurance to be most improtant, seconded by information and comfort, then support and least of all proximity (Table 1$)$.

\subsection{Ranking of the Top 14 Family Needs}

Despite the similarity in ranking of the family needs between the nurses and the family members themselves in the broad categories, the ranking between the 2 groups on individual needs were different. The ranking of the two groups on 14 perceived most important needs is shown in Table 2. For the nurses, they perceived that the 
Table 1. The nurses' and families’ needs as categorized into the need for support, comfort, information, proximity and assurance.

\begin{tabular}{ccc}
\hline Need category & $\begin{array}{c}\text { Ranking based on } \\
\text { nurses' perception } \\
\text { (\% mean score) }\end{array}$ & $\begin{array}{c}\text { Ranking based on family } \\
\text { members' perception } \\
\text { (\% mean score) }\end{array}$ \\
\hline Support & 70 & 73 \\
Comfort & 78 & 84 \\
Information & 78 & 85 \\
Proximity & 66 & 69 \\
Assurance & 90 & 92 \\
\hline
\end{tabular}

Table 2. A list of 14 priority needs identified by nurses and family members.

\begin{tabular}{|c|c|c|c|c|c|c|c|c|c|}
\hline \multirow{2}{*}{ Family needs } & \multicolumn{4}{|c|}{ Nurses' responses } & \multicolumn{4}{|c|}{ Families' responses } & \multirow{2}{*}{ p-value } \\
\hline & Rank & $\mathrm{N}$ & M & SD & Rank & $\mathrm{N}$ & M & SD & \\
\hline $\begin{array}{l}\text { To have explanations of the environment before going } \\
\text { into the critical care unit for the first time }\end{array}$ & 1 & 62 & 3.81 & 0.51 & 6 & 62 & 3.66 & 0.81 & 0.23 \\
\hline To have questions answered honestly & 2 & 62 & 3.77 & 0.61 & 9 & 62 & 3.61 & 0.82 & 0.22 \\
\hline To know why things were done for the patient & 3 & 62 & 3.77 & 0.53 & 8 & 62 & 3.63 & 0.68 & 0.19 \\
\hline To have explanations given that are understandable & 4 & 62 & 3.76 & 0.56 & 2 & 62 & 3.81 & 0.40 & 0.58 \\
\hline $\begin{array}{l}\text { To be assured that the best possible care is being given } \\
\text { to the patient }\end{array}$ & 5 & 62 & 3.73 & 0.52 & 3 & 62 & 3.79 & 0.45 & 0.46 \\
\hline To feel accepted by hospital staff & 6 & 62 & 3.73 & 0.55 & 16 & 62 & 3.55 & 0.67 & 0.11 \\
\hline To know how the patient is being treated medically & 7 & 62 & 3.68 & 0.59 & 20 & 62 & 3.45 & 0.92 & 0.11 \\
\hline To know specific facts concerning patient's progress & 8 & 62 & 3.63 & 0.63 & 13 & 62 & 3.56 & 0.84 & 0.63 \\
\hline $\begin{array}{l}\text { To be told about transfer plans while they are being } \\
\text { made }\end{array}$ & 9 & 62 & 3.63 & 0.55 & 17 & 62 & 3.53 & 0.70 & 0.39 \\
\hline $\begin{array}{l}\text { To feel that the hospital personnel care about the } \\
\text { patient }\end{array}$ & 10 & 62 & 3.60 & 0.69 & 1 & 62 & 3.84 & 0.37 & 0.02 \\
\hline To know exactly what is being done for the patient & 11 & 62 & 3.58 & 0.69 & 4 & 62 & 3.69 & 0.67 & 0.36 \\
\hline To have directions as to what to do at the bedside & 13 & 62 & 3.53 & 0.70 & 10 & 62 & 3.61 & 0.58 & 0.49 \\
\hline To feel there is hope & 17 & 62 & 3.29 & 0.82 & 5 & 62 & 3.66 & 0.57 & 0.00 \\
\hline To have good food available in the hospital & 19 & 62 & 3.26 & 0.94 & 7 & 62 & 3.65 & 0.60 & 0.00 \\
\hline
\end{tabular}

top 3 family needs were "to have explanation of the environment before going into the critical care unit for the first time; to have questions answered honestly and to know why things were done for the patient." For the families on the other hand their top 3 priorites were "to feel that the hospital personnel care about the patient; to have explanations given that are understandable and to be assured that the best possible care is being given to the patient." (Table 2).

Out of 45 individual needs of the family members in the CCFNI, there were no significant differences ( $p>$ 0.05) between the mean scores of the nurses and those of the family members in 29 individual needs. Results show that the nurses perceptions were correct in 29 out of 45 family members' individual needs. The remaining scores from 16 individual needs showed significant differences $(p<0.05)$ between the nurses' perception and actual family needs (Table 3 ). Results show that although at category level, the nurses met all the family needs, they did not meet all the specific family needs during the care of the critically ill patients.

Results show that family members scored significantly higher $(\mathrm{p}<0.05)$ than nurses on 14 statements while the nurses scored significantly higher $(p<0.05)$ than family members on only two of the statements, "to talk about the possibility of a patient's death” and “to feel it is alright to cry”. Most family members did not want to talk about the possibility of death of a critically ill relative or cry for their critically ill relatives as to do so would be misinterpreted as not wishing the patient well. 
Table 3. Scores by nurses and family members on individual needs that differed significantly $(\mathrm{p}<0.05)$ from each other.

\begin{tabular}{|c|c|c|c|c|c|c|c|c|c|}
\hline \multirow{2}{*}{ Family needs } & \multicolumn{4}{|c|}{ Nurses' responses } & \multicolumn{4}{|c|}{ Families' responses } & \multirow{2}{*}{ p-value } \\
\hline & Rank & $\mathrm{N}$ & M & SD & Rank & $\mathrm{N}$ & M & $\mathrm{SD}$ & \\
\hline $\begin{array}{l}\text { To feel that the hospital personnel care about } \\
\text { the patient }\end{array}$ & 10 & 62 & 3.60 & 0.69 & 1 & 62 & 3.84 & 0.37 & 0.02 \\
\hline To feel there is hope & 17 & 62 & 3.29 & 0.82 & 5 & 62 & 3.66 & 0.57 & 0.00 \\
\hline To have good food available in the hospital & 19 & 62 & 3.26 & 0.94 & 7 & 62 & 3.65 & 0.60 & 0.00 \\
\hline To talk about the possibility of the patient's death & 21 & 62 & 3.23 & 0.90 & 39 & 62 & 2.50 & 1.29 & 0.00 \\
\hline To have comfortable furniture in the waiting room & 23 & 62 & 3.10 & 0.84 & 11 & 62 & 3.56 & 0.69 & 0.00 \\
\hline $\begin{array}{l}\text { To know which staff members could give what type } \\
\text { of information }\end{array}$ & 27 & 62 & 2.98 & 1.03 & 15 & 62 & 3.55 & 0.72 & 0.00 \\
\hline $\begin{array}{l}\text { To know the types of staff members taking care of } \\
\text { the patient }\end{array}$ & 30 & 62 & 2.87 & 1.09 & 18 & 62 & 3.52 & 0.74 & 0.00 \\
\hline $\begin{array}{l}\text { To have someone be concerned about the relative's } \\
\text { health }\end{array}$ & 32 & 62 & 2.77 & 1.02 & 29 & 62 & 3.13 & 0.83 & 0.04 \\
\hline $\begin{array}{l}\text { To have someone to help with financial } \\
\text { problems }\end{array}$ & 33 & 62 & 2.69 & 1.02 & 28 & 62 & 3.23 & 0.93 & 0.00 \\
\hline To talk to the doctor every day & 34 & 62 & 2.62 & 1.09 & 26 & 62 & 3.24 & 1.05 & 0.00 \\
\hline $\begin{array}{l}\text { To talk about negative feelings about what has } \\
\text { happened }\end{array}$ & 37 & 62 & 2.47 & 1.16 & 21 & 62 & 3.40 & 0.84 & 0.00 \\
\hline To feel it is alright to cry & 38 & 62 & 2.37 & 1.12 & 44 & 62 & 1.61 & 1.11 & 0.00 \\
\hline $\begin{array}{l}\text { To have another person with you when visiting } \\
\text { the critical care unit }\end{array}$ & 39 & 62 & 2.31 & 1.07 & 33 & 62 & 3.02 & 1.06 & 0.00 \\
\hline $\begin{array}{l}\text { To have a specific person to call at the hospital } \\
\text { when unable to visit }\end{array}$ & 40 & 62 & 2.18 & 0.94 & 31 & 62 & 3.08 & 1.05 & 0.00 \\
\hline To visit anytime & 44 & 62 & 1.37 & 0.77 & 42 & 62 & 1.77 & 1.18 & 0.03 \\
\hline To talk to the same nurse every day & 45 & 62 & 1.32 & 0.70 & 40 & 62 & 2.32 & 1.23 & 0.00 \\
\hline
\end{tabular}

Among the nurses, there were significant differences $(\mathrm{p}<0.05)$ between registered nurses and nurse technicians on six need statements (Table 4). Five of the need satements relate to support category while the other one relates to the need for comfort. Registered nurses scored higher than nurse technicians in all the six need statements (Table 4$)$ hence they also scored significantly higher $(\mathrm{p}<0.05)$ in the two need categories of support and comfort than the nurse technicians.

Among the family members there was a significant difference $(\mathrm{p}<0.05)$ in the mean scores for individual needs between males and females (Table 5). Male family members scored significantly higher scores $(\mathrm{p}<0.05)$ than females on five need statements. Out of the five statements, three were related to the need for comfort category while the other two needs related to information and proximity categories. Overall, the male family members had a significantly high $(\mathrm{p}<0.05)$ need for comfort than their women counterparts.

\section{Discussion}

This study aimed at eliciting and comparing nurses' and families' perception of family needs in critical care unit. Generally, there were similarities between nurses' and families' rating of the individual family needs and need categories. These results are consistent with findings of similar studies [14] [15] and indicate the existence of fertile ground for mutually integrating efforts towards achieving positive patient outcomes.

The family members rated highly the need "to feel that the hospital personnel care about the patient". Nurses considered this need equally important though not perceived as top priority. This need has been reported as being common among family members with trauma and neuro patients who cannot survive without intensive care [16]. The current study cannot provide evidence to this explanation because the nature of the patient's illness was not included in the collected data. However, this finding echoes the need for health professionals to explore and understand the concept of "caring" to meet this priority need.

The family members also perceived as important the need "to have good food available in the hospital" and 
Table 4. Differences between registered nurse midwives and nurse midwife technicians scores on perceived individual family needs.

\begin{tabular}{|c|c|c|c|c|c|}
\hline \multirow{2}{*}{ Family need } & \multicolumn{2}{|c|}{ Registered nurses } & \multicolumn{2}{|c|}{$\begin{array}{c}\text { Nurse midwife } \\
\text { technicians }\end{array}$} & \multirow{2}{*}{ p-value } \\
\hline & $\mathbf{N}$ & Mean score & $\mathbf{N}$ & Mean score & \\
\hline To know why things were done for the patient & 16 & 2.94 & 46 & 2.18 & 0.008 \\
\hline To have explanations given that are understandable & 16 & 3.56 & 46 & 2.93 & 0.011 \\
\hline To be assured that the best possible care is being given to the patient & 16 & 3.75 & 46 & 3.30 & 0.21 \\
\hline To feel that the hospital personnel care about the patient & 16 & 1.93 & 46 & 1.32 & 0.003 \\
\hline To have directions as to what to do at the bedside & 16 & 3.62 & 46 & 3.21 & 0.036 \\
\hline To visit anytime & 16 & 3.25 & 46 & 2.26 & 0.000 \\
\hline
\end{tabular}

Table 5. Mean score differences among family members on individual needs in relation to their gender.

\begin{tabular}{|c|c|c|c|c|c|}
\hline \multirow{2}{*}{ Family need } & \multicolumn{2}{|c|}{ Males } & \multicolumn{2}{|c|}{ Females } & \multirow{2}{*}{ p-value } \\
\hline & $\mathbf{N}$ & Mean score & $\mathbf{N}$ & Mean score & \\
\hline To have a specific person to call at the hospital when unable to visit & 20 & 3.65 & 42 & 3.02 & 0.012 \\
\hline To have a place to be alone while in the hospital & 20 & 3.65 & 42 & 3.14 & 0.033 \\
\hline To visit anytime & 20 & 3.3 & 42 & 2.59 & 0.000 \\
\hline To feel there is hope & 20 & 3.9 & 42 & 3.59 & 0.046 \\
\hline To have a bathroom near the waiting room & 20 & 3.8 & 42 & 3.40 & 0.017 \\
\hline
\end{tabular}

"to have a bathroom near the waiting room". There is lack of evidence in the current literature to support the high ranking of these needs. This study was conducted at public central hospitals in Malawi where family members looking after patients stay at the hospital during their relative's hospitalisation. This shows that family needs could be influenced by the set up of hospitals and facilities available to relatives of patients.

Both nurses and family members perceived the needs "to be alone while in the hospital" and "to be alone at any time” as less important. According to Eggenberger and Nelms [17] family members prefer staying close to relatives to overcome the experience of critical illness. This is also prevalent in Malawi culture that reinforces social cohesion during critical illness or bereavement when even relatives that do not normally get along well, get united when there is death or illness of a family member.

The need "to visit anytime" and "to talk to the same nurse every day" were also lowly ranked by nurses. These findings are in agreement with the current literature which shows that nurses regard family members presence in critical care unit as an obstacle to nursing intervention and treatment [18]. Restrictions on patient visiting are imposed because Malawians live in extended families whereby one patient may have more guardians thus disturbing the patient's rest and escalate infections in the under resourced critical care unit.

Registered nurses had higher scores than nurse technicians on six individual need statements and two need categories (support and comfort). The nurses did not receive any training on intensive care, therefore only depended upon their pre-service knowledge. Similar variations were reported in a previous study [19]. The variations are a reflection of the differences in quality of curricula and training of state registered nurses as opposed to that of nurse technicians who are trained at certificate level. This calls for the need for authorities to support in service training for both cadre of nurses so that they are consistent in addressing family needs.

Differences in scores were noted between nurses and the family members. Families scored higher than nurses on most need items. These results are supported by available literature that report that nurses fail to predict family needs and generally underestimate emotional needs of family members [19] [20]. These results could also be the reason the nurses' scores in the present study were lower than family members' scores. The results therefore suggest that there is still room for improvement if beneficiaries of critical care are to enjoy total quality care.

\section{Conclusion}

When the major family need categories of support, comfort, information, proximity and assurance are con- 
sidered, both the nurses and family members considered that assurance was the most important need. Furthermore, nurses' perceptions and actual families' needs across these major need categories were similar. When individual family needs are considered, the findings suggest that nurses often underestimate the needs of family members. There were differences between the registered nurse midwives and nurse midwife technicians on the perception of the family needs which is attributed to the training background between the two cadre of nurses. Therefore, there is a need for continuos in service training of nurses on critical patient care. Furthermore, family members in this study perceived the needs that bring comfort and support as priority needs with male family members demanding more comfort than female family members did. It is therefore recommended that facility authorities formulate ICU and HDU policies and strategies that promote and ensure provision of services that are friendly to family members of critically ill patients.

\section{Limitations of the Study}

The ICUs included in the study admit a combined population of adults and children; and combined patients of medical, trauma, surgical, and obstetric emergencies. Paediatric ICUs often advocate for family centered care model and have unrestricted visitation policies with family members often allowed to sleep in the same room with their critically ill child and this may have affected the family members' perceived needs.

\section{Implications for Practice}

1) Nurses will be able to provide humane and dignified care to family members by giving priority to the most important family needs.

2) Findings will guide hospital authorities in the development of policies that are friendly to family members.

3) Findings will enable health authorities to have a rationale for upgrading nurses in specialised critical care training and this would improve the quality of care rendered to critically ill patients and their families.

\section{Acknowledgements}

The authors wish to express their gratitude to authorities of the three tertiary hospitals for giving permission for data collection. We also thank the nurses and family members who spared their time to participate in the study.

\section{References}

[1] Pryzby, B.J. (2005) Effects of Nurse Caring Behaviours on Family Stress Responses. Intensive and Critical Care Nursing, 21, 16-23. http://dx.doi.org/10.1016/j.iccn.2004.06.008

[2] Morton, P.G. and Fontaine, D.K. (2009) Critical Care Nursing, a Holistic Approach. 9th Edition, J.B Lippincott Company, China.

[3] Williams, C.M.A. (2005) The Identification of Family Members' Contribution to Patients' Are in the Intensive Care Unit: A Naturalistic Inquiry. Nursing in Critical Care, 10, 6-14. http://dx.doi.org/10.1111/j.1362-1017.2005.00092.x

[4] Molter, N.C. (1979) Needs of Relatives of Critically Ill Patients: A Descriptive Study. Heart \& Lung, 8, 332-339.

[5] Leske, J.S. (1986) Needs of Relatives of Critically Ill Patients: A Follow Up. Heart \& Lung, 14, 189-193.

[6] Lee, L.Y.K. and Lau, Y.L. (2003) Immediate Needs of Adult Family Members of Adult Intensive Care Patients in Hong Kong. Journal of Clinical Nursing, 12, 490-500. http://dx.doi.org/10.1046/j.1365-2702.2003.00743.x

[7] Maxwell, K.E., Stuenkel, D. and Saylor, C. (2007) Needs of Family Members of Critically Ill Patients: A Comparison of Nurse and Family Perceptions. Heart \& Lung, 36, 367-376. http://dx.doi.org/10.1016/j.hrtlng.2007.02.005

[8] Tomlison, J., Kadyaudzu, C., Samuel, C., Campbell, L.P. and Charles, A.G. (2013) The Burden of Surgical Disease on Critical Care Services at a Tertiary Hospital in Sub-Saharan Africa. Tropical Doctor, 43, 27-29. http://dx.doi.org/10.1177/0049475513480773

[9] Fowler, A.R., Adhikari, N.K.J. and Bhagwanjee, S. (2008) Clinical Review: Critical Care in the Global ConextDisparities in Burden of Illness, Access and Economics. Critical Care, 12, 225. http://dx.doi.org/10.1186/cc6984

[10] Dunser, M.W., Baelani, I. and Ganbold, L. (2006) A Review and Analysis of Intensive Care Medicine in the Least Developed Countries. Critical Care Medicine, 34, 1234-1242. http://dx.doi.org/10.1097/01.CCM.0000208360.70835.87

[11] Jochberger, S., Ismailova, F., Banda, D., Mayr, V.D., Luckner, G., Lederer, W., Wenzel, V., Wilson, I.H. and Dunser, M.W. (2010) A Survey of the Status of Education and Research in Anaesthesia and Intensive Care Medicine at the 
University Teaching Hospital in Lusaka, Zambia. Archives of Iranian Medicine, 13, 5-12.

[12] Polit, D.F. and Beck, C.T. (2008) Essentials of Nursing Research, Methods, Appraisals and Utilization. 5th Edition, Lippincott, New York.

[13] NSO (2011) National Statistical Office and ICF Macro, Malawi Demographic and Health Survey 2010, Zomba. NSO and ICF Macro, Malawi and Calverton.

[14] Moggai, F., Biagi, S. and Pompei, V. (2005) The Needs of Relatives of Patients Admitted to Italian Critical Units: A Survey Comparing Relatives' and Nurses' Perceptions. The World of Critical Care Nursing, 4, 23-26.

[15] Hinkle, J.L. and Fitzpatrick, E. (2011) Needs of American Relatives of Intensive Care Patients: Perceptions of Relatives, Physicians and Nurses. Intensive and Critical Care Nursing, 27, 2218-2225. http://dx.doi.org/10.1016/j.iccn.2011.04.003

[16] Verhaeghe, S., Defloor, T., Van Zuuren, F., Duijnstee, M. and Grypdonck, M. (2005) The Needs and Experiences of Family Members of Adult Patients in an Intensive Care Unit: A Review of the Literature. Journal of Clinical Nursing, 14, 501-509. http://dx.doi.org/10.1111/j.1365-2702.2004.01081.x

[17] Eggenberger, S.K. and Nelms, T.P. (2007) Being Family: The Family Experience When an Adult Member Is Hospitalised with Critical Illness. Journal of Clinical Nursing, 16, 1618-1628. http://dx.doi.org/10.1111/j.1365-2702.2007.01659.x

[18] Berti, D., Ferdinande, P. and Moons, P. (2007) Beliefs and Attitudes of Intensive Care Nurses toward Visits and Open Visiting Policy. Intensive Care Medicine, 33, 1060-1065. http://dx.doi.org/10.1007/s00134-007-0599-X

[19] Takman, C. and Severinsson, E. (2004) The Needs of Significant Others within Intensive Care-The Perspectives of Swedish Nurses and Physicians. Intensive and Critical Care Nursing, 20, 22-31. http://dx.doi.org/10.1016/j.iccn.2003.09.003

[20] Davidson, J.E. (2009) Family-Centred Care, Meeting the Needs of Patients' Families and Helping Families Adapt to Critical Illness. Critical Care Nurse, 29, 28-34. http://dx.doi.org/10.4037/ccn2009611 